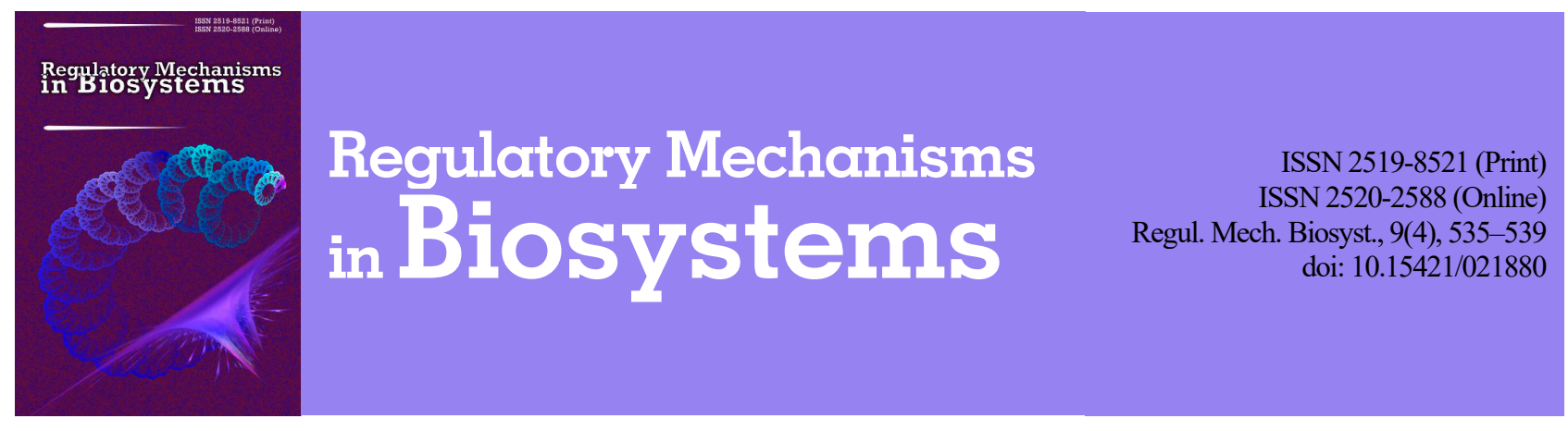

\title{
Optimization of Ginkgo biloba cultivation technology in open soil conditions
}

\author{
I. M. Kovalenko*, G. O. Klymenko*, R. A. Yaroschuk*, M. I. Fedorchuk**, O. A. Lykholat*** \\ *Sumy' National Agricultural University, Sumy, Ukraine \\ **Mykolayiv National Agrarian University, Mykolayiv, Ukraine \\ ***University of Customs and Finance, Dnipro, Ukraine
}

Article info

Received 17.10.2018

Received in revised form

12.11.2018

Accepted 16.11.2018

Sumy National Agrarian University, G. Kontratyev st., 160, Sumy, 40021, Ukraine. Tel.: +38-095-407-72-48. E-mail:

annaklimenko2014@gmail.com

Mykolayiv National

Agrarian University

Georgiva Gongadze st., 9 ,

Mykolayiv, 54020, Ukraine.

Tel.: +38-051-234-10-82.

E-mail: rector@mnau.edu.ua

University of Customs

and Finance,

Volodymyr Vernadskyst., 2/4,

Dnipro, 49000, Ukraine

Tel.: +38-056+745+55+96

E-mail:

university.msf@gmail.com

\begin{abstract}
Kovalenko, I. M., Klymenko, G. O., Yaroschuk, R. A., Fedorchuk, M. I., \& Lykholat, O. A. (2018). Optimization of Ginkgo biloba cultivation technology in open soil conditions. Regulatory Mechanisms in Biosystems, 9(4), 535-539. doi:10.15421/021880
\end{abstract}

In recent years, interest in cultivating Ginkgo biloba L. as a medicinal plant has grown in Ukraine, and improvement of the technology of growing this plant in the conditions of the North-East of Ukraine is a relevant problem. The purpose of this article to present research on the morphological structure, growth and viability of young G. biloba plants in grown from seeds by different technologies and comparative analysis of growth and development of G. biloba plants under greenhouse conditions and on open soil. The experiment on G. biloba cultivation was initiated in 2014 in three variants (the plants were grown from the seeds). Variant No 1: G. biloba growing in a greenhouse at $60-80 \%$ humidity and temperatures not below $+27^{\circ} \mathrm{C}$; shading (shading level $60 \%$ ) by green agronetting. Variant No 2: growing in open soil; shading (shading level $60 \%$ ) by green agronetting; the climatic conditions were typical for Sumy region. Variant No 3: growing in open soil; there was no shading; climatic conditions were typical for the Sumy region. Plant analysis was conducted in June 2018. The following morphometric parameters of G. biloba plants were measured: plant height, annual growth of shoots, number of leaves, leaf size and leaf area, phytomass of the shoots, phytomass of leaves and phytomass of the stem, diameter of the shoots. The sampling used 60 samples. The leaf area was determined by the method of drawing contours on millimeter paper. Statistical processing of research results was carried out by generally accepted modern methods of mathematical statistics using dispersion, correlation, regression and vital analysis. In the conditions of the Ukrainian North East, G. biloba seedlings can be grown successfully in greenhouses and open soil, both with $60 \%$ shade by agronetting and without it. Differences between the plants grown in such conditions are insignificant and statistically unreliable. The obtained three to four year old G. biloba seedlings grown using different technologies were $25-30 \mathrm{~cm}$ in height and formed 13-17 leaves per plant. The seedlings were of quite high viability (Q is $0.22-0.30)$ and morphostructural integrity $(67.8 \%)$. The output of viable seedlings (vital classes "a" and "b") in variant 1 was $60 \%$, variant $2-45 \%$ and variant $3-60 \%$. Ecologicalcenotic stability of G. biloba was observed repeatedly, though certain limitations on G. biloba cultivation may be that the plant is photophilic and thermophilic. But the conducted experiments show that the climatic conditions of the Ukrainian North-East are quite favourable for this species. Based on the data obtained for the Ukrainian North-East, it is possible to recommend the technology of growing G. biloba seedlings in open soil without agronetting as quite effective and low-cost.

Keywords: medicinal plants; cultivation technology; morphometric parameters; correlation analysis; vital analysis

\section{Introduction}

Among the many medicinal plants (Boyko \& Brygadyrenko, 2016; Kovalenko et al., 2017; Khromykh et al., 2018a, 2018b), Ginkgo biloba L. is distinguished by a number of features. This is a woody plant, a relic of the Mesozoic period, which is extremely rare in its natural range (only in China). The leaves of G. biloba are distinguished by a combination of unique medicinal properties, and therefore G. biloba trees are cultivated artificially in a number of countries (Mohanta et al., 2014; Torchik et al., 2018). The leaf extract is used in the treatment of various vascular diseases (atherosclerosis, prophylaxis of heart attacks and strokes), hypertension, it has a protective effect on brain tissue, improves memory, increases mental and physical capacity, has anti-stress action, raises immunity and has many other useful properties.

G. biloba leaves are rich in calcium, magnesium, potassium, copper ions, sulfur and phosphorus, silicon. It contains a complex of biologically active biochemical compounds. The pharmacological patent extract of Biloba EGb 761 contains 24\% flavonoid glycosides and 6\% ginkolipids and bilobalids, and all other active substances in the extract are also preserved. Beta-sitosterol as the main component of G. biloba extract helps to slow the growth of tumours of the prostate, colon and breast, activates the production of female sex hormones, relieves cramps, improves metabolism, prevents the formation of gallstones, and reduces menopause symptoms (Mohanta et al., 2014; Heinonen \& Gaus, 2015; Lykholat et al., 2016; Badore et al., 2017; Qiu et al., 2017; Zhang \& Cai, 2018).

Research results give grounds to speak about the complex effect of the standardized extract of this relic species, which improves cognitive function, reduces the clinical manifestations of vascular pathology of the brain, improves sleep and motor activity (Krauss et al., 2016; Fan et al., 2018). Leaf extract improves cerebrovascular flow and supplies oxygen and glucose to the brain, increases concentration, relieves mental fatigue, reduces the inattention and frequency of headache and dizziness. In addition, G. biloba extract is effective in treating emotional overload, greatly increases concentration and performance (Chen et al., 2016; Li et al., 2017). With these benefits in mind, collected, crushed and dried G. biloba leaves are used by pharmaceutical companies to produce about 70 different drugs for the prevention and treatment of dozens of diseases in different countries. Also, leaves of this species are actively used in agriculture for growing plants in saline soils (Çavuşoğlu \& Karaferyeli, 2015) and to improve soil properties (Si et al., 2017).

The question of plantation cultivation of this relict for the purpose of harvesting leaves for pharmaceutical purposes began acquire practi- 
cal significance in 1982, when the first industrial plantations were established in the USA (South Carolina) and France (the Bordeaux region). Their areas were 460 and 480 hectares, respectively. Somewhat later a plantation was planted in Ireland. In 1992, such plantations were laid in eastern China. Their total area was more than 2,000 hectares. Four years later, the first batch of leaves of the studied introduced species was received in these plantations. In 2010, the total area of G. biloba plantations was more than 5,000 hectares in China.

Currently, in the United States, France, Germany, South Korea, and other countries this relict plant is grown for pharmacological needs (as medicinal tea), on industrial plantations ranging from several dozens to hundreds of hectares each (Rimkiene et al., 2017). At the same time, scientists emphasize the fact that the process of growing plantations of this relic species can affect the productivity and concentration of active substances in the leaf (Yang \& Chen, 2014; Guo et al., 2016; Rimkiene et al., 2017). Given the fact that this species is relict, research on the conservation of G. biloba is also being conducted (Tasiu, 2015).

In this regard, interest in cultivating $G$. biloba as a medicinal plant has grown in Ukraine. From processing $50 \mathrm{~kg}$ of dry leaves one $1 \mathrm{~kg}$ of extract is obtained. At present, as a pharmaceutical raw material G. biloba leaf is purchased at a price from 66 to $80 \mathrm{UAH}$ per $100 \mathrm{~g}$.

The species was first cultivated in Ukraine in the Kremenets Botanical Garden in 1811. Now, G. biloba is cultivated as single specimens in virtually all areas of Ukraine. For this species, a wide ecological flexibility is characterized by its bioecological features such as frost resistance, photophilia, response to soil fertility, and resistance to air pollution. Individually located individuals grow better on fresh, aerated soils. The worst growth indicators are for specimens on dry, sealed soils. Thus, among the trees of the four growth groups growing under optimal growth conditions the two-leafing ginkgo are attributed to the trees of the first magnitude, the height of which is more than $25 \mathrm{~m}$, since the specimens of this species reach $30-40 \mathrm{~m}$ and a diameter of $3.0-4.5 \mathrm{~m}$, although trees reach 20-25 (30) $\mathrm{m}$ high in the West Ukraine conditions (Zayachuk et al., 2016).

Improving the technology of growing this plant is an urgent task in the conditions of the North-East of Ukraine. Currently, in creating plantations of the studied species for harvesting leaves for pharmaceutical purposes in the Ukrainian North-East, there are a number of problems:

- the single and uneven distribution of G. biloba hinders the mass harvest of seed and leaves for medicinal purposes in the research area;

- lack of awareness of functioning pharmaceutical companies about the possibility of purchasing the leaves of this relic harvested in Ukraine for medicinal purposes.

To solve these problems, it is recommended to promote:

- mass cultivation of the introduced species as a medicinal raw material by creating plantations of special purpose in the studied region;

- involvement of mass media and direct communication with the leadership of domestic pharmaceutical companies.

Consequently, the following benefits of G. biloba plantation cultivation can be singled out in the Ukrainian North-East:

- positive economic effect: since G. biloba leaves will be harvested and processed in Ukraine, the price for it in the dried state for the manufacture of tea and medicines, which includes alcohol extract from the leaves of the studied species, will significantly decrease, which will have a positive effect for consumers;

- ecological effect: the new plantation will, in the first place, contribute to improving the oxygen balance in the surrounding areas;

- aesthetic effect: the leaves of the introduced species have a decorative form, due to which the plant can be used in landscaping areas.

The purpose of this research is to study the morphological structure, growth and viability of young plants $G$. biloba grown from the seeds by different technologies and conduct comparative investigation of $G$. biloba plants growth and development under greenhouse conditions and open soil.

\section{Material and methods}

G. biloba is a deciduous tree with a height of $30 \mathrm{~m}$ and a trunk diameter up to $3 \mathrm{~m}$. According to the current classification, G. biloba refers to the division of lower seed plants (Spermatophyta), the subunit of seed plants (Spermatophytina), the Ginkgo (Ginkgoopsida) class, the Ginkgo order (Ginkgoales) (Stankovic, 2016). This is a two-domed anemophilous plant. In G. biloba, the reproduction process begins at the age of 25-30 years. Microstrobiles are formed on "male" plants and have the look of earrings. Microspores are without air bags. G. biloba megastrobiles are formed on "female" plants and consist of a long leg and seated on it two seeded rudiments. In nature, pollination occurs by the wind carrying microspores at considerable distances in the spring.

The seeds have a soft juicy shell. The seed embryo is surrounded by an endosperm. Seeds sprout in autumn and require stratification in spring crops. In culture, G. biloba is propagated by seeds, root cuttings or stem cuttings (Rimkiene et al., 2017).

G. biloba leaves have a specific structure. They are fanlike in form, leathery, bare, slightly comugated along the edge, lacquered-green. The leaf blade is wide with a wedge-shaped base and dichotomous venation. It is usually cut out and has a more or less deep V-shaped cutout on top, which cleaves the sheet plate to two symmetrical halves. Critchfield (1970) shows that leaves with a deep V-shaped cutout are typical for elongated shoots, and leaves without such a cut or with a shallow weak cutout for shortened ones. The leaves forming on truncated shoots are thinner, and their photosynthetic potential is lower (Leigh et al., 2011). Depending on the conditions of growing, leaf blades are asymmetric, and the degree of their asymmetry is an indicator of various stressors effect on the plants.

G. biloba plants have been grown from seeds, because it has previously been shown this plant is equally successful when cultivated from seed and with vegetative propagation (Rimkiene et al., 2017).

The experiment on G. biloba cultivation was founded in 2014 in three variants: Variant No 1: G. biloba growing in a greenhouse at 60$80 \%$ humidity and temperatures not below $+27^{\circ} \mathrm{C}$; shading (shading level $60 \%$ ) by green agronetting. Variant No 2: growing in open ground; shading (shading level $60 \%$ ) by green agronetting; climatic conditions typical for the Sumy region. Variant No 3: growing in open soil; there is no shading; climatic conditionss typical for the Sumy region. The general view of the plantation G. biloba (variant No 3) is presented in Figure 1.

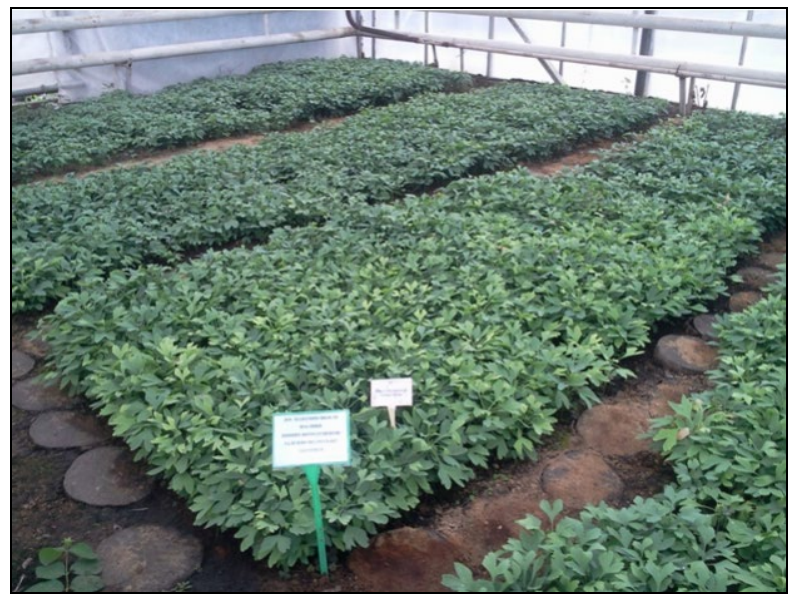

Fig. 1. General view of G. biloba plantation in SNAU

Plant analysis was conducted in June 2018. The following morphometric parameters of the G. biloba plants were measured (Skliar \& Sherstuk, 2016; Klymenko et al., 2017; Kovalenko et al., 2017); plant height, annual growth of shoots, number of leaves, leaf size and leaf area, phytomass size of shoots, phytomass of leaves and phytomass of the stem, diameter of the shoots. The sampling included 60 samples. The leaf area was determined by the method of drawing leaf contours on millimeter paper.

Theoretical foundations and algorithm of the vital analysis were formulated by Zlobin et al. (2013). During the conduct of the vital analysis, individuals are divided into three categories of quality: high (A), intermediate (B) and lower (C). This division is carried out on the basis of the key, or determinants of the vitality of the individual morphostructural features. Usually, there are three such features. The determination 
of key features is an independent stage of the vitality analysis procedure. For its solution, it is evaluated: a) the biological significance of each of the signs for the biomorph; $b$ ) variability degree of the feature from the individual to the individual, assuming that the more varied features have a lot of informative value; c) the degree of correlation between the signs, striving to the features included in the key ones weren't highly correlated and didn't belong to the same correlation galaxy; d) the factor loads of the characteristics obtained during the factor analysis, selecting them so that the signs with the highest factor loadings were included in the composition key ones.

Depending on the ratio in the population of different vitality classes individuals, populations are valued as flourishing, balanced or depressed. The integral estimate of the populations quality (Zlobin et al., 2013) is the index $\mathrm{Q}(\mathrm{Q}=0.5 \cdot(\mathrm{a}+\mathrm{b}))$, whose value is in the range from 0 to 0.5 ( $\mathrm{a}$ - individuals of the highest vitality class, $\mathrm{b}$-intermediate ones).

Based on the vital analysis, high-quality populations were identified: depressed $(\mathrm{Q}<0.167)$, balanced ( $\mathrm{Q}$ from 0.167 to 0.333 ), flourishing $(\mathrm{Q}>0.333)$. For the determination of the vital structure of the populations, a formalized algorithm and a special computer program VITAL were used that allowed us to complete the vital analysis in stages. The content analysis consisted of only statistically significant $(\mathrm{P}<0.05)$ results (Zlobin et al., 2013).

The correlation degree of morphometric parameters was determined by calculating the index of morphological integration of plants. Morphometric parameters are correlated differently: high positive or negative correlation coefficients between two pairs of signs, or vice versa, low correlation indices between pairs of signs, reflecting a low dependence between the compared parts of the plant. Usually between positive and high values of correlation coefficients predominate between the signs. Under stress conditions, the degree of correlation of plant structures changes. In some cases, in the stressed conditions of plants, correlation degree of the correlation matrix and, consequently, the integrity of the morphological structure increase. In others, on the contrary, the connectivity of the matrix decreases under more hostile growth conditions. Based on this, a method for assessing plant species condition - correlation adaptometry was designed. Regular morphological structures are considered as the plant organism integrity indicator. To determine the morphological integrity of plant species, the following index as the most effective one was used (Zlobin et al., 2013):

$$
\mathrm{I}=\mathrm{B} /\left(\left(\mathrm{n}^{2}-\mathrm{n}\right) / 2\right) \cdot 100 \%,
$$

where I - index of morphological integration, i.e. integrity of the individual, B - the number of statistically reliable (at the probability level of 0.95 ) correlation coefficients in the matrix, $\mathrm{n}$ - the total number of morphometric parameters taken into account.

The Honesty Significant Difference test or Tukey's HSD test (Mcdonald, 2014) was used to compare the mean values of the selections. This criterion allows one to correctly perform multiple paired comparison of averages. The average difference is considered statistically significant with a confidence probability of $\mathrm{P}<0.05$. The calculation of Tukey's posteriori multiple Twin pair criterion was made in the computerized package of applied statistical programs Statgraphics Centurion XV V 15.1.02.

\section{Results}

The average values of morphometric parameters of $G$. biloba plants in the three variants of the experiment are given in Table. 1. It is determined that leaf area is closely related to the width of its leaf blade and corresponds to the equation $y=-16.598+6.628 x$ at $R^{2}=0.997$. The graph of this dependence is presented in Figure 2. It has been shown in different experimental variants the plants differ in a number of morphometric parameters. When growing in a greenhouse or open soil the largest variation was observed for such parameters as the value of the annual growth of the main shoots and the size of the leaf surface.

When cultivated in the greenhouse (variant 1), G. biloba plants showed a slightly larger amount of annual growth of shoots and, accordingly, height. Growing G. biloba in open soil with shading (variant 2) contributed to the enhanced development of aboveground part of the plants. This technology provided greater phytomass of shoots and larger phytomass of leaves. In variant 3 (open soil without shading), more leaves were formed and their total surface was higher.

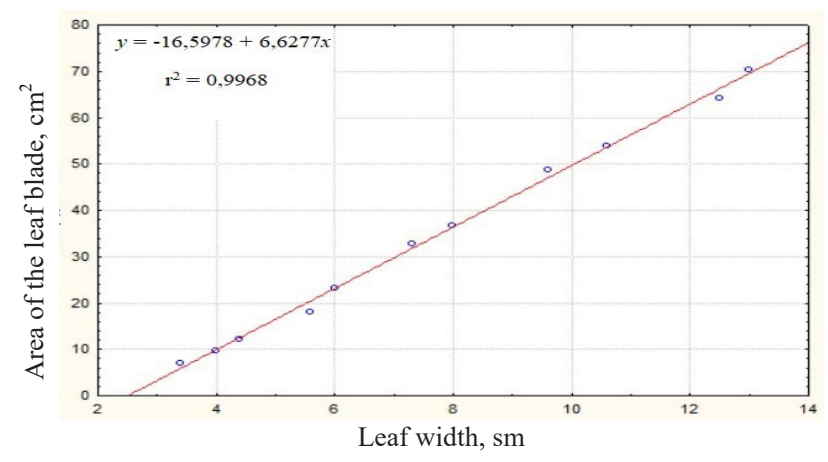

Fig. 2. Dependence of G. biloba leaf area $\left(\mathrm{cm}^{2}\right)$ on the width of the leaf blade $(\mathrm{cm})$

Table 1

Average values of morphometric parameters and their errors in

G. biloba plants depending on growing technology $(\mathrm{x} \pm \mathrm{SD}, \mathrm{n}=20)$

\begin{tabular}{lccc}
\hline \multirow{1}{*}{\multicolumn{1}{c}{ Index }} & \multicolumn{3}{c}{ Growing conditions } \\
\cline { 2 - 4 } & $\begin{array}{c}\text { closed soil } \\
\text { (greenhouse) }\end{array}$ & $\begin{array}{c}\text { open soil with } \\
\text { shading }\end{array}$ & $\begin{array}{c}\text { open soil } \\
\text { without shading }\end{array}$ \\
\hline Plant height, cm & $29.5 \pm 2.32^{\mathrm{a}}$ & $25.6 \pm 1.81^{\mathrm{ab}}$ & $26.7 \pm 1.01^{\mathrm{ab}}$ \\
Annual growth, cm & $15.6 \pm 0.78^{\mathrm{a}}$ & $5.4 \pm 1.27^{\mathrm{b}}$ & $10.3 \pm 0.89^{\mathrm{c}}$ \\
Number of sheets, pcs & $13.9 \pm 1.82^{\mathrm{a}}$ & $13.5 \pm 1.13^{\mathrm{a}}$ & $16.5 \pm 2.11^{\mathrm{ab}}$ \\
Phytomass leaves, g & $5.4 \pm 0.75^{\mathrm{a}}$ & $5.9 \pm 0.59^{\mathrm{a}}$ & $4.9 \pm 0.69^{\mathrm{ab}}$ \\
Phytomass of the plant & $8.7 \pm 1.17^{\mathrm{a}}$ & $9.1 \pm 0.85^{\mathrm{a}}$ & $8.2 \pm 0.84^{\mathrm{ab}}$ \\
above-ground part, g & & & \\
Diameter of the main & $0.385 \pm 0.0213^{\mathrm{a}}$ & $0.443 \pm 0.0137^{\mathrm{b}}$ & $0.415 \pm 0.0159^{\mathrm{a}}$ \\
stem, cm & & & \\
Leaf surface, cm ${ }^{2}$ & $540 \pm 70.8^{\mathrm{a}}$ & $525 \pm 43.9^{\mathrm{a}}$ & $667 \pm 89.3^{\mathrm{b}}$ \\
\hline
\end{tabular}

Note: the same Latin letters in a row mean statistically insignificant differences in the mean of the compared pairs by the Tukey test $(\mathrm{P}<0.05)$.

According to statistical data processing results, the differences of G. biloba individuals were statistically significant only by the magnitude of the annual growth of the main shoots in the experiment variants. This confirms that in the greenhouse cultivation of G. biloba seedlings leads to the growth of plants, with significantly greater height of annual shoots growth, and, accordingly, the plants are higher in the comparable calendar year. However, stem diameter was smaller in comparison with the plants from open soil. According to other morphological characteristics, such plants didn't have any advantage, which indicates a shortage of photosynthetic active radiation in the greenhouse. Therefore, G. biloba plants grown in greenhouse conditions can have more difficulty in adapting to further transplantation into open soil.

For integral evaluation of $G$. biloba plant viability, vitality analysis has been used. Its results showed (Table 2), in all experimental variants on the morphometric characteristics that the aggregate of G. biloba plants corresponded to balanced type agropopulation, in which there are individuals of all three vital types a, b, and c in close relationships. But at the same time, a higher proportion ( $40 \%$ ) of the class "a" individuals was in the variant with the cultivation of G. biloba in greenhouse conditions. The smallest proportion of higher vitality individuals (only 20\%) was formed with G. biloba cultivated in the open soil without the protection by agronetting. The plants grown in a greenhouse, and plants from open soil without agronetting had higher vitality $(\mathrm{Q}=0.300)$. G. biloba individuals from open soil, but with netting protection (variant 2), had vitality index $\mathrm{Q}=0.225$.

The vitality of $G$. biloba plants from variant 2 (open soil with a protective netting) was inferior to the plants from variants 1 and 3 . It is shown in the general agropopulation of $G$. biloba individuals, the largest share of plants of the highest class of vitality was in the variant 2 : it was $55 \%$ of the total number of individuals.

According to investigation results (Table 3) from 28 correlation coefficients between morphometric parameters characterizing status of G. biloba plants, 19 were statistically significant, that is more than half. The greatest independence was due to two parameters: the magnitude of annual growth and the diameter of the plants' stem. The rest of the morphological structures proved to be quite closely correlated with each other. Thus, for G. biloba, the morphological integration index was equal 
to $67.8 \%$. This is a high rate indicating that the conditions for G. biloba cultivation are stressful for it in all three variants.

Table 2

Analysis of vitality of $G$. biloba agropopulation

\begin{tabular}{cccccc}
\hline \multirow{2}{*}{ Variants } & \multicolumn{2}{c}{ Frequencies of vitality class } & \multirow{2}{*}{ Vitality, Q } & \multirow{2}{*}{ Type of vitality } \\
\cline { 2 - 4 } & $\mathrm{a}$ & $\mathrm{b}$ & $\mathrm{c}$ & & \\
\hline 1 & 0.400 & 0.200 & 0.400 & 0.300 & balanced \\
2 & 0.300 & 0.150 & 0.550 & 0.225 & balanced \\
3 & 0.200 & 0.400 & 0.400 & 0.300 & balanced \\
\hline
\end{tabular}

Table 3

Correlation coefficients

between morphometric parameters of $G$. biloba plants $(\mathrm{n}=20)$

\begin{tabular}{|c|c|c|c|c|c|c|c|c|}
\hline Parameters & 䔅 & 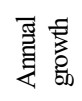 & 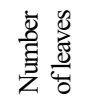 & 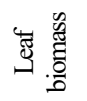 & 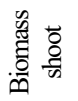 & 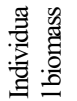 & 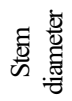 & 峞 \\
\hline Height & - & - & - & - & - & - & - & - \\
\hline Annual growth & 0.378 & - & - & - & - & - & - & - \\
\hline Number of leaves & 0.422 & 0.212 & - & - & - & - & - & - \\
\hline Leaf biomass & $0.662^{* *}$ & 0.139 & $0.724^{* * *}$ & - & - & - & - & - \\
\hline Biomass shoot & $0.856^{* * *}$ & 0.273 & $0.511^{*}$ & $0.779^{* * *}$ & - & - & - & - \\
\hline Individual biomass & $0.764^{* * *}$ & 0.193 & $0.689^{* *}$ & $0.976^{* * *}$ & $0.896^{* * *}$ & - & - & - \\
\hline Stem diameter & 0.059 & -0.234 & 0.323 & 0.242 & 0.234 & 0.252 & - & - \\
\hline Leaf surface & 0.422 & 0.212 & $1.000^{* * *}$ & $0.724^{* * *}$ & $0.511^{*}$ & $0.689^{* *}$ & 0.323 & - \\
\hline
\end{tabular}

\section{Discussion}

G. biloba is widely cultivated and the species also occurs naturally. The International Union for the Conservation of Nature (IUCN), based on research, has classified G. biloba as an "endangered species" (Fu \& Jin, 1992). Specialists have developed and proposed two main conservation strategies - selection of highly productive individuals and distribution of effective methods of development (Schmid \& Balz, 2005).

The species has existed on our planet for 270 million years without changes, and it is considered to be a "missing link" between gymnosperms and angiosperms (Zhou \& Zheng, 2003). G. biloba trees exhibit extremely slow growth with very weak regeneration through the seeds; vegetative reproduction through cuttings is the most appropriate way of spreading. High germination ability has allowed the species to be preserved in the mountains with erosive slopes and played a role in its survival with morphological stability (Del Tredici \& van Beek, 2000). Plants show high resistance to environmental stress, microbial diseases (fungal, viral and bacterial), other pests and gaseous pollutants as ozone and $\mathrm{SO}_{2}$, making them suitable for greening the cities. Based on this, G. biloba is considered as a model for studying plant resistance and stress (Mohanta, 2012). Ecological and coenotic stability of G. biloba was observed repeatedly during its cultivation in different geographical regions (Meena, 2015; Stankovic, 2016; Torchik et al., 2018). Guo et al. (2016) have identified the subsequent treatment of $G$. biloba individuals by mineral fertilizers containing $\mathrm{N}-400 \mathrm{~g}, \mathrm{P}-200 \mathrm{~g}, \mathrm{~K}-90 \mathrm{~g}$ per tree is the most effective.

Leaves and seeds of G. biloba have long been used in Chinese phytotherapy. Modern studies focus mainly on the standardization of the G. biloba extract obtained from dried green leaves (Tasiu, 2015). Fifty million $G$. biloba trees, grown primarily in China, France and the USA (South Carolina), produce over 8,000 tons of dry leaves annually, which are used as medicinal raw materials (Nakanishi, 2005). Studies on determining the antioxidant properties of $G$. biloba have shown this index is higher in the leaf than the branches (Tewari et al., 2017) and depends on leaf colour (Wojdyło et al., 2007). The medicinal properties of G. biloba plants are significantly influenced by environmenalt abiotic and biotic factors associated with altitude and seasons (Ellnain-Wojtaszek et al., 2003; Kaur et al., 2012), and also the growing site affects active substances (flavanoid) concentration in the leaves (Rimkiene et al., 2017). It has been proved (Sati et al., 2013) that the largest number of phytochemicals and antioxidants is related on autumn and spring (depending on substance type). At the same time, it has been proven (Rimkiene et al., 2017) that the place of cultivation and the harvesting time greatly influence the active substances (flavanoid) concentration in G. biloba leaf: July and August are most suitable for industrial harvesting.

Paleobotanic studies have shown that the species was widespread worldwide in the past (Tasiu, 2015) while there is currently a pressing need for its conservation (Tewari et al., 2017) through comprehensive population studies (Zlobin et al., 2013; Klymenko et al., 2017). This plant is characterized by high drought tolerance. The ecological amplitude of the species is quite broad, despite the fact that $G$. biloba enjoys fertile well-aerated soils of medium mechanical composition. According to the research results (Zayachuk et al., 2016) on biometric indices of G. biloba in the arboretum of VLNC "Berezinka" State Enterprise "Mukachevo Forestry", a low degree of crown deflation and a good sanitary state of the G. biloba trees were detected. G. biloba leaves and wood contain insect repellent substances that allow the use of the plant leaves and parts in compost ( $\mathrm{Si}$ at al., 2017) to improve soil quality and root crop cultivation (Çavuşoğlu \& Karaferyeli, 2015). Therefore, in Ukraine, the plants aren't damaged by insects and are resistant to diseases.

Many experts have shown that in unfavourable conditions there is a "destruction" of interactions between individual modules in plants (Zlobin et al., 2013). Our studies have shown G. biloba cultivation conditions, due to the index of morphological integration, are stressful for it.

Certain limitations on $G$. biloba cultivation may be this plant is photophilic and thermophilic. But the experiments conducted show that the climatic conditions the Ukrainian North-East are quite favourable for it, as well as other regions of Ukraine (Zayachuk et al., 2016). Taking into account the value of the investigated relic species, the promise and success of its introduction, it can be argued that the creation of G. biloba plantations for the purpose of harvesting leaves for pharmaceutical purposes would be economically significant.

In the conditions of the Ukrainian North East, $G$. biloba seedlings can be grown sufficiently successfully in greenhouses and open ground, both with $60 \%$ shade by agronetting and without it. Differences between the plants grown in such conditions are insignificant and statistically unreliable. The three to four year old $G$. biloba seedlings grown under various technologies were $25-30 \mathrm{~cm}$ high and formed 13-17 leaves per plant. The seedlings had a fairly high viability $(Q=0.22-0.30)$ and morphostructural integrity $(67.8 \%)$. The output of viable seedlings (vital classes "a" and "b") in variant 1 was $60 \%$, variant $2-45 \%$ and variant $3-60 \%$. Based on the data obtained for the North-East of Ukraine, it is possible to recommend the technology of growing $G$. biloba seedlings in open soil without agronetting as quite effective and low-cost.

\section{Conclusions}

The perspectives and expediency of G. biloba cultivation as a medicinal raw material in the Ukrainian North-East was determined. Despite the stress conditions of cultivation for G. biloba, this species is characterized by high resistance and adaptability, which is confirmed by our comparative morphometric and vital analysis of the plants. Given the fact that the seedlings were still young, further research is required to determine the adaptability of $G$. biloba plants to growing conditions.

\section{References}

Badore, N. S., Das, P. K., Pillai, S., \& Thakur, A. (2017). Role of Ginkgo biloba extract, against isoproterenol induced cardiac toxicity in rats. Indian Journal of Pharmaceutical Education and Research, 51(4), 691-699.

Boyko, A. A., \& Brygadyrenko, V. V. (2016). Influence of water infusion of medicinal plants on larvae of Strongyloides papillosus (Nematoda, Strongyloididae). Visnyk of Dnipropetrovsk University. Biology, Ecology, 24(2), 519-525.

Çavuşoğlu, K., \& Karaferyeli, Ş. (2015). Effects of Ginkgo biloba L. extract on the seed germination, seedling growth and leaf anatomy of barley under saline conditions. Bangladesh Journal of Botany, 44(1), 117-123.

Chen, L. E., Wu, F., Zhao, A., Ge, H., \& Zhan, H. (2016). Protection efficacy of the extract of Ginkgo biloba against the learning and memory damage of rats under repeated high sustained $+\mathrm{Gz}$ exposure. Evidence-based complementary and Alternative Medicine, 2016, 6320586.

Critchfield, W. (1970). Shoot growth and heterophylly in Ginkgo biloba. Botanical Gazette, 131(2), 150-162. 
Del Tredici, P., \& van Beek, T. A. (2000). The evolution, ecology, and cultivation of G. biloba. In: Ginkgo biloba. Harwood Academic Publishers, Netherlands.

Ellnain-Wojtaszek, M., Kruczyński, Z., \& Kasprzak, J. (2003). Investigation of free radical scavenging activity of Gingko biloba L. leaves. Fitoterapia, 74, 1-6.

Fan, Y., Jin, X., Man, C., \& Gong, D. (2018). Does adjuvant treatment with Ginkgo biloba to statins have additional benefits in patients with dyslipidemia? Frontiers in Pharmacology, 9, 659.

Fu, L. G., \& Jin, J. M. (1992). Chinese plant Red Data Book: Rare and endangered plants. Vol. 1. Science Press, Beijng.

Guo, J., Wu, Y., Wang, B., Lu, Y., Cao, F., \& Wang, G. (2016). The effects of fertilization on the growth and physiological characteristics of Ginkgo biloba L. Forests, 7(12), 293

Heinonen, T., \& Gaus, W. (2015). Cross matching observations on toxicological and clinical data for the assessment of tolerability and safety of Ginkgo biloba leaf extract. Toxicology, 327, 95-115.

Kaur, P., Chaudhary, A., Singh, R. D., Prasad, G. R. P., \& Singh, B. (2012). Spatial and temporal variation of secondary metabolite profiles in Ginkgo biloba leaves. Chemistry Biodiversity, 9, 409-417.

Khromykh, N. O., Lykholat, Y. V., Kovalenko, I. M., Kabar, A. M., Didur, O. O., $\&$ Nedzvetska, M. I. (2018b). Variability of the antioxidant properties of Berberis fruits depending on the plant species and conditions of habitat. Regulatory Mechanisms in Biosystems, 9(1), 56-61.

Khromykh, N., Lykholat, Y., Shupranova, L., Kabar, A., Didur, O., Lykholat, T., \& Kulbachko, Y. (2018a). Interspecific differences of antioxidant ability of introduced Chaenomeles species with respect to adaptation to the steppe zone conditions. Biosystems Diversity, 26(2), 132-138.

Klymenko, A., Kovalenko, I., Lykholat, Y., Khromykh, N., Didur, O., \& Alekseeva, A. (2017). The integral assessment of the rare plant populations. Ukrainian Journal of Ecology, 7(2), 201-209.

Kovalenko, I. M., Klymenko, H. O., \& Hozhenko, K. H. (2017). Population analysis of Asarum europaeum in the Northeast of Ukraine. Biosystems Diversity, 5(3), 210-215.

Krauss, P., Tziridis, K., Buerbank, S., Schilling, A., \& Schulze, H. (2016). Therapeutic value of Ginkgo biloba extract EGb $761^{\circledR}$ in an animal model (Meriones unguiculatus) for noise trauma induced hearing loss and tinnitus. PLoS One, 11(6), e0157574.

Leigh, A., Zwieniecki, M. A., Rockwell, F. E., Boyce, C. K., Nicotra, A. B., \& Holbrook, N. M. (2011). Structural and hydraulic correlates of heterophylly in Ginkgo biloba. New Phytologist, 189, 459-470.

Li, S., Zhang, X., Fang, Q., Zhou, J., Zhang, M., Wang, H., Chen, Y., Xu, B., Wu, Y., Qian, L., \& Xu, Y. (2017). Ginkgo biloba extract improved cognitive and neurological functions of acute ischaemic stroke: A randomised controlled trial. Stroke and Vascular Neurology, 2, 189-197.

Lykholat, T., Lykholat, O., \& Antonyuk, S. (2016). Immunohistochemical and biochemical analysis of mammary gland tumours of different age patients. Cytology and Genetics, 50(1), 32-41.

Meena, R. L. (2015). Standardization of propagation and agrotechniques in Ginkgo biloba L. - a medicinally important plant. Journal of Medicinal Plants Studies, $3(4), 6-15$.

Mohanta, T. K. (2012). Advances in Ginkgo biloba research: Genomics and metabolomics perspectives. African Journal Biotechnology, 11(159) 36-44.
Mohanta, T. K., Tamboli, Y., \& Zubaidha, P. K. (2014). Phytochemical and medicinal importance of Ginkgo biloba L. Natural Product Research, 28(10), 746-752.

Nakanishi, K. (2005). Terpene trilactones from Ginkgo biloba: From ancient times to the 21 st century. Bioorganic and Medicinal Chemistry, 13, 4987-5000.

Qiu, J., Chen, X., Netrusov, A. I., Zhou, Q., Guo, D., Liu, X., He, H., Xin, H., Wang, Y., \& Chen, L. (2017). Screening and identifying antioxidative components in Ginkgo biloba pollen by DPPH-HPLC-PAD coupled with HPLC-ESI-MS2. PLoS One, 12(1), e0170141.

Rimkiene, L., Kubiliene, A., Zevzikovas, A., Kazlauskiene, D., \& Jakstas, V. (2017). Variation in flavonoid composition and radical-scavenging activity in Ginkgo biloba L. due to the growth location and time of harvest. Journal of Food Quality, 2017, Article ID 6840397.

Sati, P., Pandey, A., Rawat, S., \& Rani, A. (2013). Phytochemical and antioxidant in leaf extracts of Ginkgo biloba with reference to location, seasonal variation and solvent system. Journal of Pharmacy Research, 7(9), 804-809.

Schmid, W., \& Balz, J. (2005). Cultivation of Ginkgo biloba L. on three continents. Acta Hort (ISHS), 676, 177-180.

Si, W., Luan, Y., Li, J., \& Mao, X. (2017). Use of Ginkgo biloba leaf compost for promoting soil properties and rooting of New Guinea impatiens cuttings. Biological Agriculture and Horticulture, 33(4), 258-268.

Skliar, V., Sherstuk, M. (2016). Size structure of phytopopulations and its quantitative evaluation. Eureka: Life Sciences, 1, 9-16.

Stankovic, M. (2016). Biology and ecology of Ginkgo biloba L. (Ginkgoaceae). In: Ginkgo biloba: Biology, uses and health benefits. Nova Science Publishers, New York.

Tasiu, I. (2015). Rethinking Ginkgo biloba L.: Medicinal uses and conservation. Pharmacognosy Reviews, 9(18), 140-148.

Torchik, V. I., Holopuk, G. A., \& Kel'ko, A. F. (2018). Perspektivy introdukcii ginkgo dvulopastnogo (Ginkgo biloba L.) v Belarusi [Prospects for the introduction of Ginkgo biloba L. in Belarus]. Izvestija Nacional'noj Akademii Nauk Belarusi, Serija Biologicheskih Nauk, 63(1), 27-32 (in Russian).

Wojdyło, A., Oszmiański, J., \& Czemerys, R. (2007). Antioxidant activity and phenolic compounds in 32 selected herbs. Food Chemistry, 105(3), 940-949.

Yang, X., \& Chen, G. (2014). Stimulation of photosynthetic characteristics of Ginkgo biloba L. during leaf growth. Bangladesh Journal of Botany, 43(1), 73-77.

Zayachuk, V. Y., Khomiuk, P. G., Khomiuk, A. P., Pogribnyj, O. O., \& Yurkevych, A. O. (2016). The structure and the sanitary state of ginkgo biloba (Ginkgo biloba L.) tree stand in the Arboretum VLNS "Berezinka" of the Mukachevo State Forestry Enterprise. Scientific Bulletin of UNFU, 26(5), 41-48 (in Ukrainian).

Zhang, X., \& Cai, Y. (2018). Effects of Ginkgo biloba leaf extract, shenmai and matrine on a human embryonic lung fibroblast fibrosis model. Experimental and Therapeutic Medscine, 16(5), 4289-4295.

Zhou, Z., \& Zheng, S. (2003). The missing link in Ginkgo evolution. Nature, 423(6942), 821-822.

Zlobin, J. A., Skljar, V. G., \& Klimenko, A. A. (2013). Populjacii redkih vidov rastenij: Teoreticheskie osnovy i metodika izuchenija [Populations of rare plant species: Theoretical foundations and methods of study]. Universitetskaja Kniga, Sumy (in Russian). 